\title{
Prelude to THEMIS tail conjunction study
}

\author{
A. T. Y. Lui ${ }^{1}$, Y. Zheng ${ }^{1}$, Y. Zhang ${ }^{1}$, V. Angelopoulos ${ }^{2}$, G. K. Parks ${ }^{2}$, F. S. Mozer ${ }^{2}$, H. Rème ${ }^{3}$, L. M. Kistler ${ }^{4}$, \\ M. W. Dunlop ${ }^{5}$, G. Gustafsson ${ }^{6}$, and M. G. Henderson ${ }^{7}$ \\ ${ }^{1}$ JHU/APL, Laurel, MD 20723-6099, USA \\ ${ }^{2}$ Space Sciences Laboratory, UCB, Berkeley, CA, USA \\ ${ }^{3}$ CESR, BP4346, 31028 Toulouse Cedex 4, Toulouse, France \\ ${ }^{4}$ University of New Hampshire, Durham, NH, USA \\ ${ }^{5}$ Space Science and Technology Department, RAL, Chilton, Didcot, Oxfordshire OX11 0QX, UK \\ ${ }^{6}$ Swedish Institute of Space Physics, Uppsala Division, 75591 Uppsala, Sweden \\ ${ }^{7}$ LANL, MS D466, Los Alamos, NM, USA
}

Received: 4 December 2006 - Revised: 6 April 2007 - Accepted: 13 April 2007 - Published: 8 May 2007

\begin{abstract}
A close conjunction of several satellites (LANL, GOES, Polar, Geotail, and Cluster) distributed from the geostationary altitude to about $16 R_{E}$ downstream in the tail occurred during substorm activity as indicated by global auroral imaging and ground-based magnetometer data. This constellation of satellites resembles what is planned for the THEMIS (Time History of Events and Macroscopic Interactions during Substorms) mission to resolve the substorm controversy on the location of the substorm expansion onset region. In this article, we show in detail the dipolarization and dynamic changes seen by these satellites associated with two onsets of substorm intensification activity. In particular, we find that dipolarization at $\sim 16 R_{E}$ downstream in the tail can occur with dawnward electric field and without plasma flow, just like some near-Earth dipolarization events reported previously. The spreading of substorm disturbances in the tail coupled with complementary ground observations indicates that the observed time sequence on the onsets of substorm disturbances favors initiation in the near-Earth region for this THEMIS-like conjunction.
\end{abstract}

Keywords. Magnetospheric physics (Magnetospheric configuration and dynamics; Magnetotail; Storms and substorms)

\section{Introduction}

Magnetospheric substorms exhibit impulsive energy release in many regions within the magnetosphere. One outstanding fundamental question is the location of the process responsible for substorm expansion onset. One school of

Correspondence to: A. T. Y. Lui

(tony.lui@jhuapl.edu) thought proposes the initiation location to be in the nearEarth region about 6 to $15 R_{E}$ downstream in the tail (Lui, 1991, 2004; Roux et al., 1991; Cheng and Lui, 1998; Pu et al., 1999, 2001; Cheng, 2004). Another school proposes the initiation location to be in the mid-tail region about 20 to $30 R_{E}$ (Haerendel, 1992; Shiokawa et al., 1997, 1998; Nagai et al., 1998). Seeking an answer to this controversy is the central focus of the NASA mission called Time History of Events and Macroscale Interactions during Substorms (acronym THEMIS) (http://sprg.ssl.berkeley.edu/ themis/about_themis.html). THEMIS is designed to have five spin-stabilized satellites aligned nearly along the tail axis at downstream distances from about 10 to $30 R_{E}$ such that the origin of substorm onset disturbances may be pinned down. It also has complementary ground-station observations of auroral activity (Donovan et al., 2006). With the multiple satellites in operation during the International Solar Terrestrial Physics (ISTP) era, there are intervals of satellite conjunction that mimic to some degree the satellite constellation desired by the THEMIS mission (e.g., Lui et al., 2000; Sergeev et al., 2005). These intervals may be considered as a prelude to the events that would be examined in detail by THEMIS.

In this paper, we investigate in detail one substorm interval on 8 August 2003 when several satellites spanning from the geostationary altitude to $\sim 16 R_{E}$ downstream in the magnetotail were making measurements. The satellites contributing to this study include geostationary satellites from Los Alamos National Laboratory (LANL) and GOES 12, ISTP satellites of Polar and Geotail, and European satellites of Cluster II consisting of four satellites. Complementary to this study are ground magnetic stations and TIMED satellite with remote-sensing of global auroral disturbances in both the Northern and the Southern Hemispheres. Two major onsets of substorm disturbances were observed during the

Published by Copernicus GmbH on behalf of the European Geosciences Union. 


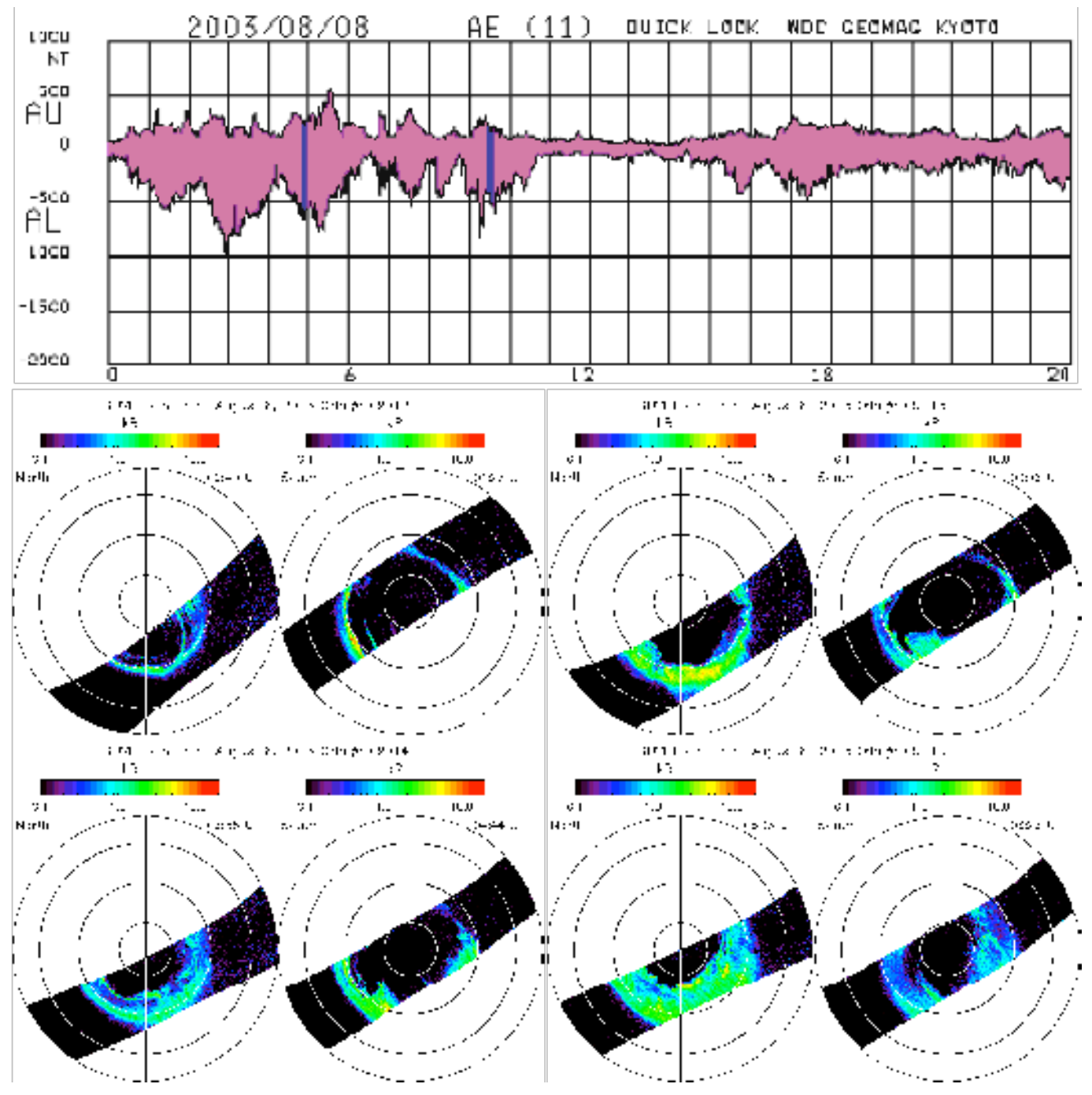

Fig. 1. The AU (upper) and AL (lower) indices on 8 August 2003 and the sequence of global auroral images from TIMED as it crossed over each polar region.

conjunction interval. Since there was rather continuous magnetic activity on the ground, these two onsets may be intensifications of the ongoing substorm activity. From the time sequence of activity onset at various locations in the magnetotail and on the ground, we have found evidence from the observations that favors the onset location to be in the nearEarth region for these two activity onsets.

\section{Observations}

\subsection{Ground activity}

The ground magnetic activity on 8 August 2003 indicated by the AU/AL indices and the global auroral images from TIMED/GUVI are shown in Fig. 1. The time interval of favorable satellite conjunction is between 04:00 and 06:00 UT.
There is a noticeable enhancement of the auroral electrojet strength around 04:20 UT, leading to a minimum AL index at $\sim 05: 20$ UT. The global auroral distribution observed by the TIMED/GUVI imager is shown below the AU/AL panel. The GUVI images are constructed from the LBH-short band emission data from horizon-to-horizon sweeps as the satellite crosses the polar region. The time given at each image panel corresponds to the center time of the image construction and the notations North and South denote the Northern and the Southern Hemispheres, respectively. This sequence of images indicates several substorm disturbances. In particular, the image at 04:44 UT (the second image from the left in the bottom row) shows that substorm expansion had already started at that time.

A closer look at the ground magnetic disturbances shown in Fig. 2 reveals more information on where the substorm 

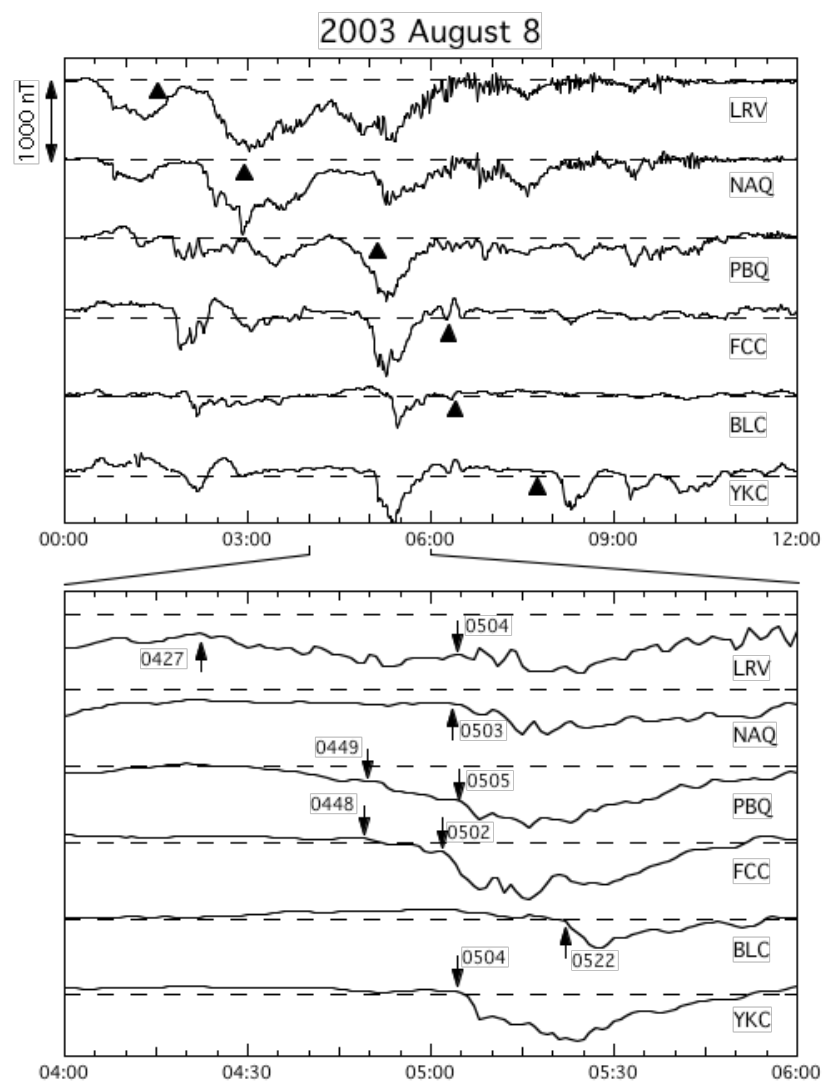

Fig. 2. The X-component of magnetic field from ground-based magnetometers. The bottom plot contains the same set of magnetic stations with the same vertical scale but for a shorter time span (04:00-06:00 UT).

activity began in magnetic local time. In this figure that shows the X-component from several stations (H-component for LRV), the local magnetic midnight for each station is indicated by the triangular symbol below the reference dashed line for the corresponding trace. Magnetic disturbances in the 04:00-06:00 UT interval were first recorded by the LRV station located in the post-midnight sector, followed by the PBQ station located very close to midnight, and then by the FCC, YKC, and BLC stations located in the pre-midnight sector. This temporal development indicates that the activity started in the post-midnight sector first, followed by activity at the pre-midnight sector. More specifically, the H-component of LRV showed a relatively sharp decrease at $\sim 04: 27$ UT, followed by a noticeable intensification at $\sim 05: 04$ UT. Since the second intensification rose above the previous activity at $\sim 500 \mathrm{nT}$ level, the onset of this intensification is likely to be earlier than $\sim 05: 04$ UT. The X-component of NAQ did not show a significant perturbation corresponding to the first intensification at LRV (probably due to the high magnetic latitude of NAQ at that magnetic local time), but detected the second intensification at 05:03 UT. At PBQ situated near the magnetic midnight

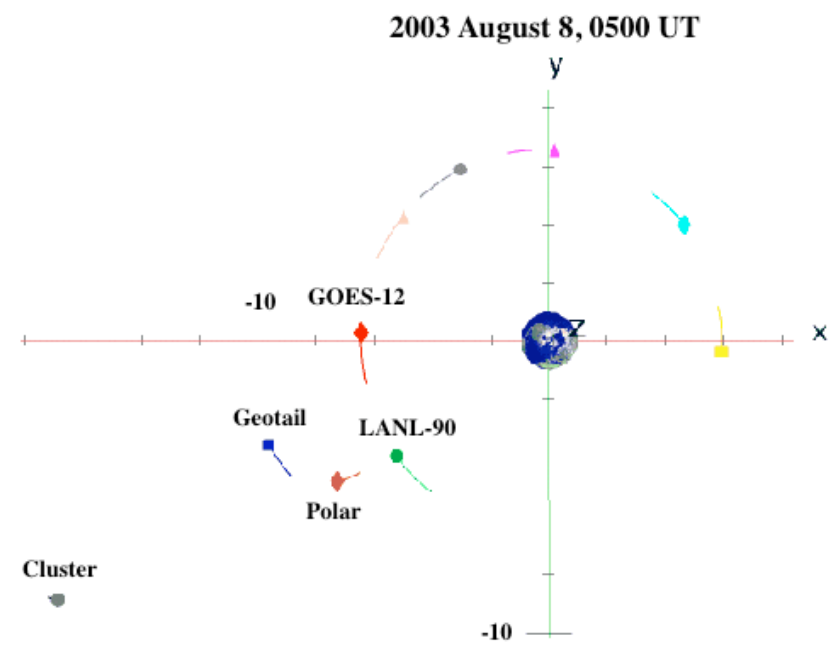

Fig. 3. The location of several satellites in the magnetotail during this substorm activity interval. The length of the trace associated with each satellite symbol represents the distance traveled by the satellite in 1-h interval after the epoch time of 05:00 UT on 8 August 2003.

and at a lower latitude than both LRV and NAQ, there were two relatively sharp decreases in the X-component, one at $\sim 04: 49$ UT and the other at $\sim 05: 05$ UT. The X-component of FCC showed a gradual decrease at $\sim 04: 48$ UT, followed by a sharp one at $\sim$ 05:02 UT. The sharp decrease at FCC was accompanied by a similar sharp decrease of the YKC $\mathrm{X}$-component at $\sim 05: 04$ UT but a more gradual decrease at BLC X-component followed by a sharper one at $\sim 05: 22 \mathrm{UT}$. Onset of substorm intensification in the post-midnight sector during this interval is supported by observation of an auroral intensification in the post-midnight sector at $\sim 04: 48$ UT by the VIS Earth camera on Polar (at $\sim 6$ min time resolution, courtesy of J. B. Sigwarth; data not shown here).

From these magnetic disturbance onsets on the ground and TIMED GUVI as well as Polar VIS data, it is clear that there was rather continuous substorm activity during this period. However, it can also be recognized that there were at least two onsets of substorm intensification recorded by more than one magnetic station on the ground. These times are 04:4804:49 UT and 05:02-05:05 UT, with the first activity concentrated mostly in the post-midnight sector and the second one covering both the pre-midnight and post-midnight sectors. These intensifications are separated by $\sim 13-16$ min apart.

\subsection{Magnetotail activity}

The satellite conjunction for this study is shown in Fig. 3 with satellite locations at 05:00 UT plotted. In the geostationary altitude are three GOES and four LANL satellites. In particular, GOES 12 was almost right at the midnight meridian at that time and LANL 90 was in the post-midnight sector. At progressively downstream distance in the magnetotail are 


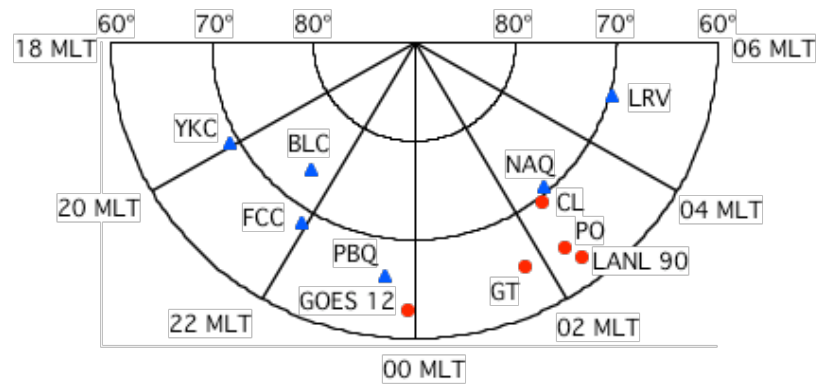

Fig. 4. The magnetic field line projections of satellites based on the T96 magnetic field model to show their footprints with respect to several ground magnetic stations. The station locations are marked with solid triangles and the satellite footprints are marked with solid circles.

Polar, Geotail, and Cluster. In order to relate magnetotail activity from these satellites to the ground activity, we have projected these satellite locations to the ground based on Tsyganenko magnetic field model (T96). Their locations relative to the ground stations are illustrated in Fig. 4.

Let us examine data from satellites at progressively further downstream distance in the magnetotail. Figure 5 shows energetic electron data from six LANL satellites. In particular, LANL 1990-095 (the bottom panel), which was at $Y_{\mathrm{GSM}} \sim-$ $3.8 R_{E}$ in the post-midnight sector where the substorm activity first started as indicated on the ground, detected a small but significant injection occurring at $\sim 04: 29$ UT, followed by a prominent injection at $\sim 04: 54$ UT. This second intensification at LANL 1990-095 was also accompanied by slightly enhanced electron intensity at other geostationary satellites in the morning and post-midnight sectors (LANL-02A and LANL-01A). The time separation between these two injections is $\sim 25 \mathrm{~min}$, noticeably longer than the time separation of substorm intensifications identified by more than one magnetic station on the ground. However, since LRV at the post-midnight sector registered the magnetic disturbance onset at $\sim 04: 27$ UT, the small injection at $\sim 04: 29$ UT is consistent with this activity onset and is probably spatially localized such that other ground magnetic stations were not affected. The effect of the subsequent substorm intensification at $\sim 04: 48-04: 49$ UT was probably masked by the injection at $\sim 04: 29$ UT.

From magnetic field measurements shown in Fig. 6, GOES 12 at $Y_{\mathrm{GSM}} \sim 0.7 R_{E}$ observed a sharp dipolarization at $\sim 04: 51 \mathrm{UT}$, followed by a short recovery and another significant dipolarization at $\sim 05: 03$ UT. These two dipolarizations were separated in time by $\sim 12 \mathrm{~min}$, close to the time separation of substorm intensifications on the ground. It may be noticed that the increase in the $B_{z}$ component at GOES 12 started at $\sim 04: 40$ UT. However, unlike the two dipolarizations later, this increase in the $B_{z}$ component was transient and weak. In addition, it was accompanied by an increase in the $B_{x}$ component indicative of a further increase in the

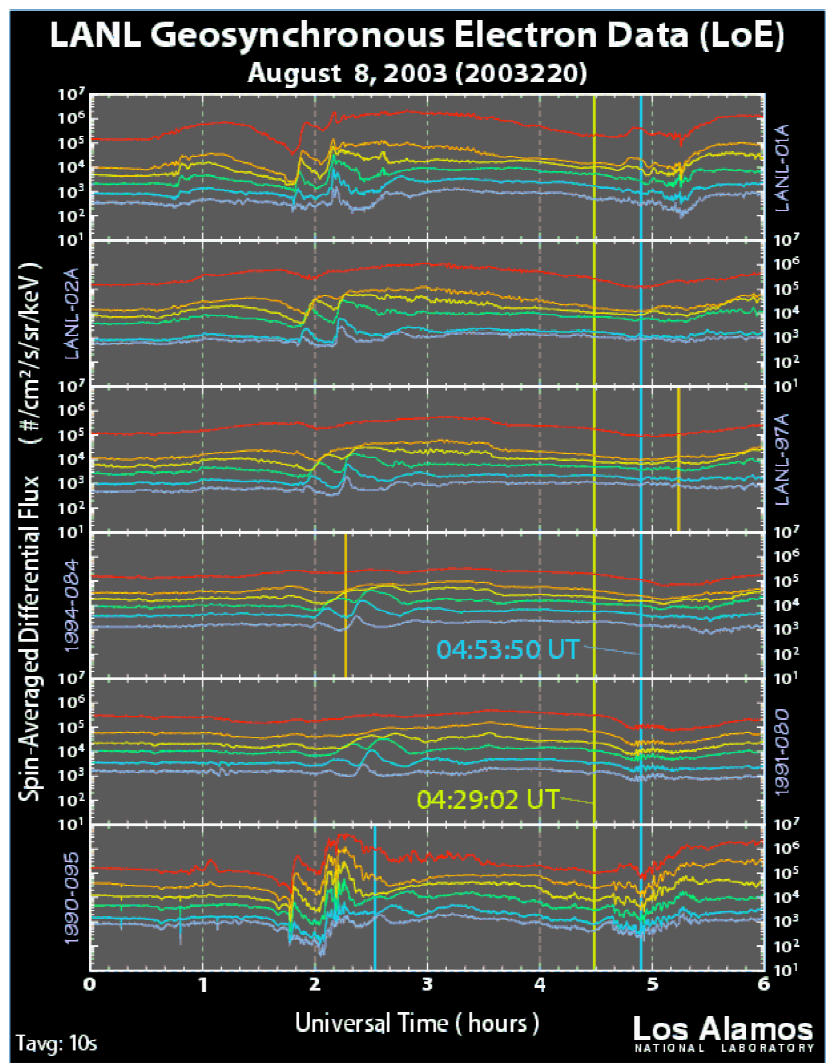

Fig. 5. The intensities of energetic electrons at several LANL geostationary satellites.

magnetic field energy at that location. Thus, the increase in the $B_{z}$ component at $\sim 04: 40$ UT is not interpreted here as a dipolarization onset. Another point worth noting is that there was no clear signature at GOES 12 corresponding to the 04:29 UT ground onset, indicating that the activity onset at 04:29 UT was quite localized.

Polar at this time was located at $\sim(-7.2,-4.7,1.7) R_{E}$ in GSM coordinates. Polar observations of electric and magnetic fields given in Fig. 7 show entry to the central plasma sheet at $\sim 04: 59$ UT. Substorm disturbance registered at 04:48-04:49 UT on the ground (FCC and PBQ) only reached Polar at this late time possibly because Polar was quite far from the central plasma sheet. The entry was accompanied by intense and highly variable electric field. Upon entry, the $B_{x}$ component stayed at the same strength for $\sim 1$ min before starting to decrease while the $B_{z}$ component increased gradually. About $10 \mathrm{~min}$ later, Polar detected a sharp change in the $B_{z}$ component at $\sim 05: 11 \mathrm{UT}, \sim 12 \mathrm{~min}$ after the plasma sheet entry. This time separation is close to the time separation of the two substorm intensifications on the ground.

Further downstream than Polar was Geotail, at $\sim(-9.7$, $-3.6,-0.8) R_{E}$ in GSM coordinates at this time. The plasma measurements at Geotail are given in Fig. 8, showing a slight 


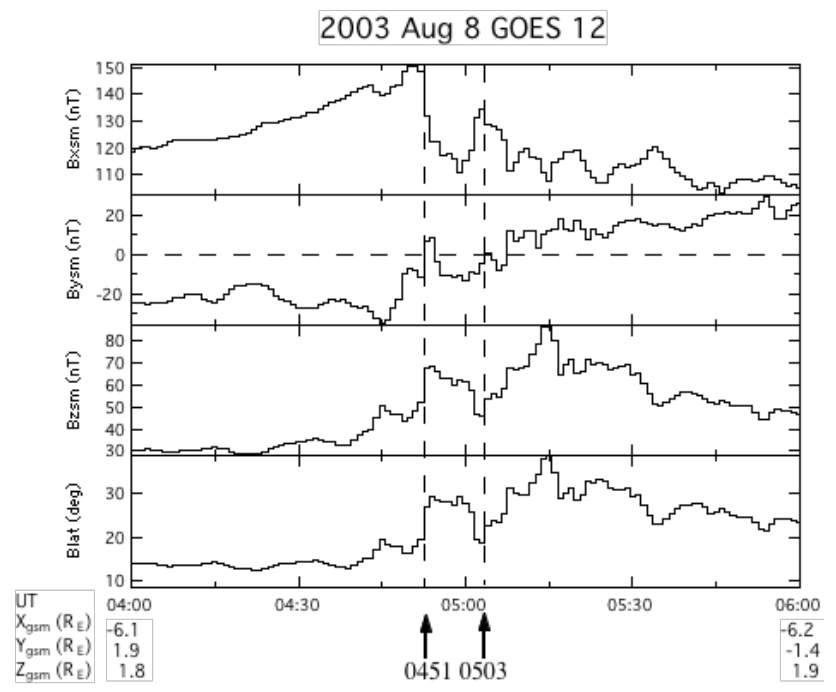

Fig. 6. The magnetic field measurements from the GOES 12 satellite.

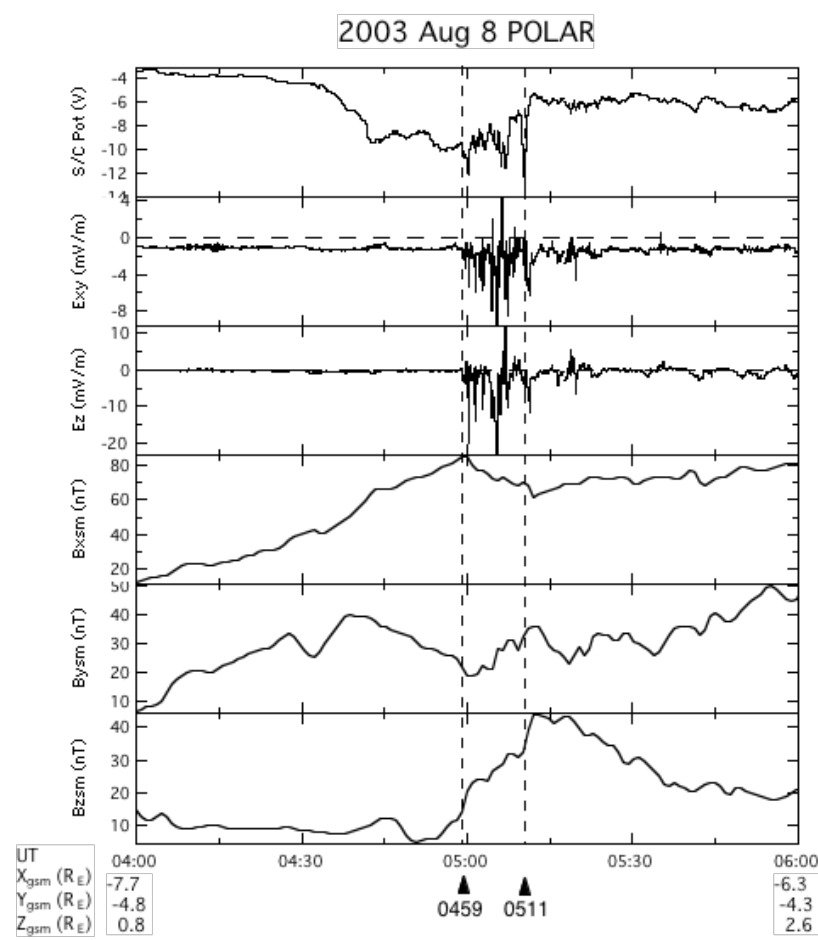

Fig. 7. The measurements from the Polar satellite. The $E_{x y}$ component points tailward while the $E_{z}$ component points northward.

increase in the $B_{z}$ component at $\sim 04: 57$ UT. This increase was accompanied by a noticeable decrease in the magnitude of the $B_{x}$ component and is thus interpreted as a small and gradual dipolarization. This change was followed by a brief dropout and then detection of a significant dipolarization at $\sim 05: 07$ UT with accompanying decrease in the $B_{x}$ component. This dipolarization was associated with moderate
2003 Aug 8 (220) GEOTAIL/LEP/MGF/EFD

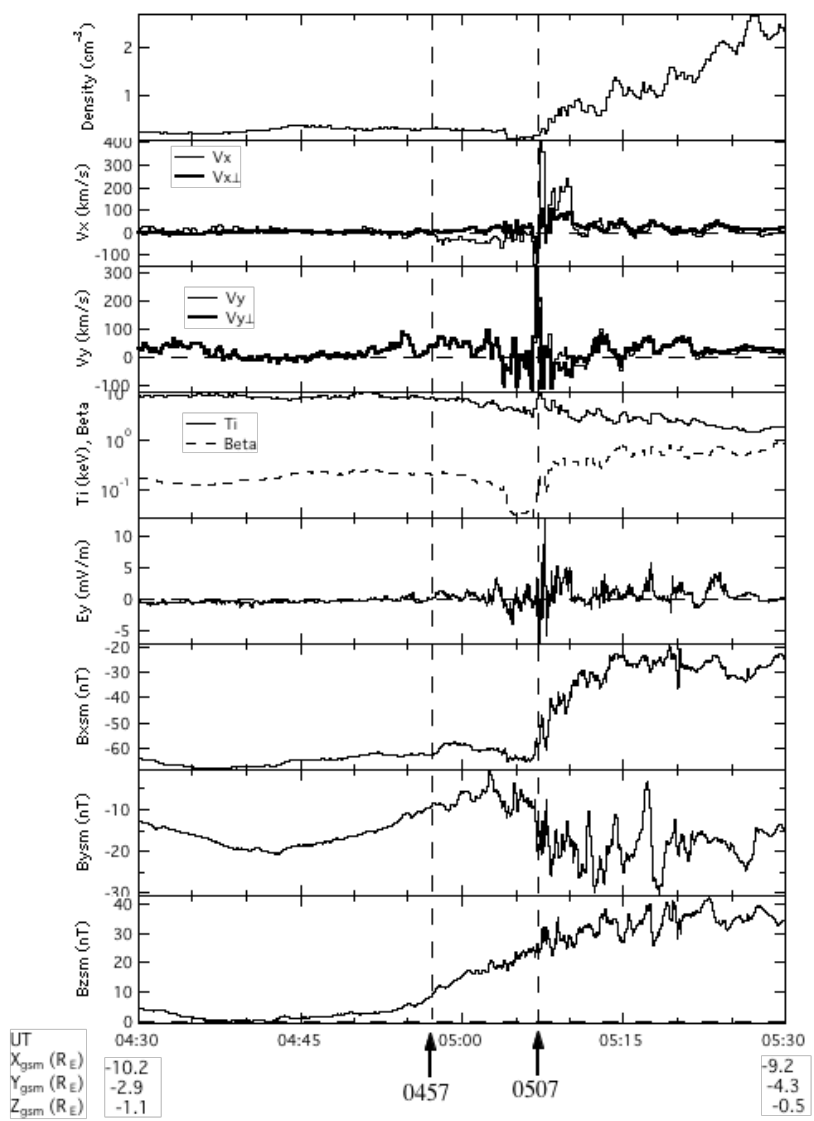

Fig. 8. The measurements from the Geotail satellite.

plasma flow, mainly field-aligned for the $x$-component, and highly variable magnetic and electric fields. The plasma flow was initially tailward at a slow speed $(\sim 100 \mathrm{~km} / \mathrm{s})$ and then switched to earthward at a faster speed $(\sim 400 \mathrm{~km} / \mathrm{s})$. There was a substantial duskward flow component at $\sim 300 \mathrm{~km} / \mathrm{s}$ that was mainly perpendicular to the magnetic field. The $y$-component of the electric field changed sign rapidly and fluctuated between about $-7 \mathrm{mV} / \mathrm{m}$ and $13 \mathrm{mV} / \mathrm{m}$ during this dipolarization. The time separation between these two dipolarizations was $\sim 10 \mathrm{~min}$, also close to the time separation of the two substorm intensifications on the ground.

Cluster satellites were located at the furthest downstream distance of $\sim(-15.8,-8.1,3.7) R_{E}$ in GSM coordinates. The Cluster measurements are given in Fig. 9. Since measurements from the four Cluster satellites were almost identical (the separation distances between the satellites were $\sim 200 \mathrm{~km}$ ), only the measurements from SAMBA (C3) are shown. SAMBA observed a gradual increase in the $B_{z}$ component at $\sim 05: 11$ UT when it was in the plasma sheet boundary layer. This increase was not accompanied by any significant decrease in the $B_{x}$ component and is thus not regarded as a dipolarization event. It may simply reflect a change in 


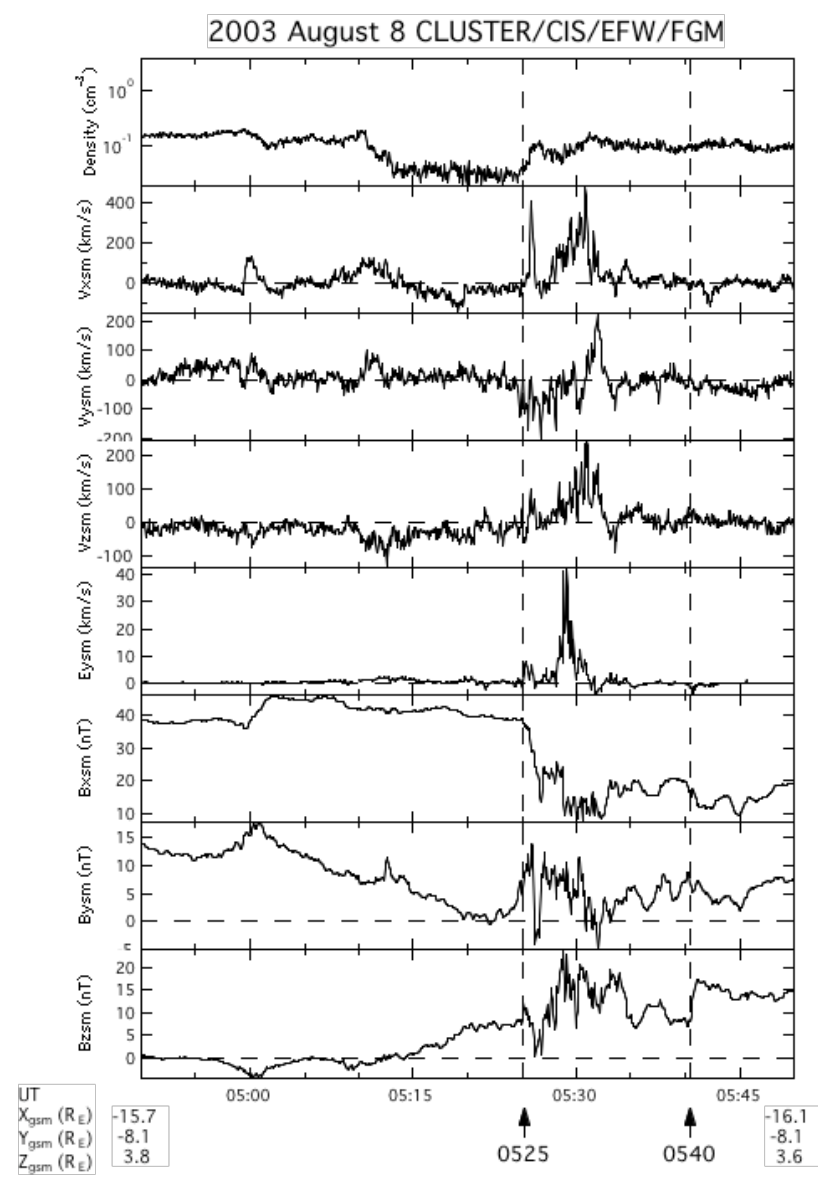

Fig. 9. Cluster measurements of plasma bulk flow from CIS/HIA (Rème et al., 2001), $y$-component of the electric field from EFW (Gustafsson et al., 2001), and magnetic field from FGM (Balogh et al., 2001).

magnetospheric current elsewhere affecting the local magnetic field. This change was later followed by an entry to the central plasma sheet at $\sim 05: 25 \mathrm{UT}$, similar to the sequence of activity seen by Geotail. After the central plasma sheet entry, SAMBA detected moderate plasma flow and a very transient southward magnetic field at 05:26 UT. Subsequent to these activities, there was a distinct dipolarization at $\sim 05: 40 \mathrm{UT}$, which is indicated by an increase in the $B_{z}$ component accompanied by a decrease in the $B_{x}$ component. Interestingly, there was no plasma flow activity and a dawnward component of the electric field $\left(E_{y}=-3.7 \mathrm{mV} / \mathrm{m}\right)$ associated with this significant change in the magnetic field. This is important as it indicates that local dipolarization can occur in the absence of plasma flow and dawnward electric field. These features have been observed in other dipolarization events in the near-Earth magnetotail (Lui et al., 1999). The time separation between central plasma sheet entry and subsequent dipolarization is $\sim 15 \mathrm{~min}$, consistent with the time separation between the two substorm intensifications noted on the ground.

\subsection{Time line of activity}

In the 2-h interval studied here, there were rather continuous magnetic and auroral activities. As a result, the substorm expansion onset time is unclear. However, there were at least two significant intensifications registered by more than one ground magnetic station. The first one started in the late postmidnight sector at $\sim 04: 27$ UT spreading to the midnight sector at $\sim 04: 48-04: 49$ UT. The second intensification occurred at 05:02-05:05 UT spanning the pre-midnight sector to the post-midnight sector. The time sequence in the magnetotail is quite clear in spite of continuous substorm activity indicated by the ground magnetometers and by global auroral observations from satellites. For the first intensification at 04:48-04:49 UT, the time sequence is LANL90 - GOES 12 - Geotail - Polar - Cluster. For the second major intensification at 05:02-05:05 UT, the time sequence is also LANL90 - GOES 12 - Geotail - Polar - Cluster. Time line of activity for these two intensifications is listed in Table 1.

\section{Summary and discussion}

\subsection{Summary}

We have examined a substorm interval on 8 August 2003 during which several satellites spanning the downstream distance from $\sim 6$ to $\sim 16 R_{E}$ in the magnetotail have detected substorm activity for two intensifications. Based on ground magnetic stations, these intensifications were initiated in the post-midnight sector and spread into the pre-midnight sector subsequently. Most of the satellites in the magnetotail (LANL 90, Polar, Geotail, and Cluster) were in the postmidnight sector. For the first minor intensification started at $~ 04: 27$ UT as indicated by the LRV magnetogram, the time sequence of activity onset is LANL 90, GOES 12, Geotail, Polar, and Cluster. For the second major intensification, the first indication of activity came from a significant particle injection detected by LANL 90 at $~ 04: 54$ UT. The time sequence of activity is also LANL 90, GOES 12, Geotail, Polar, and Cluster.

\subsection{Determination of the time sequence of substorm activ- ity}

The procedure we have adopted here in considering the spreading of substorm disturbance is by projecting satellite locations via magnetic field lines onto the ground for comparison with onsets of substorm disturbance at ground stations. This essentially reduces the three dimensional coordinates of satellites in space to two dimensional coordinates for comparison with ground activities, thus minimizing the uncertainty due to different satellite locations relative to the neutral sheet. In essence, the projection combines the dependence of radial distance and distance from the neutral sheet for satellites into a single variable of magnetic latitude. In 
Table 1. Time line of substorm disturbances.

\begin{tabular}{|c|c|c|c|}
\hline \multirow{2}{*}{\multicolumn{2}{|c|}{$\begin{array}{l}\text { Minor substorm intensification } \\
\text { Activity description }\end{array}$}} & \multicolumn{2}{|r|}{ Major substorm intensification } \\
\hline & & Time & Activity description \\
\hline 04:27 & $\begin{array}{l}\text { Onset of ground magnetic disturbance at } \\
\text { LRV in the post-midnight sector }\end{array}$ & $04: 54$ & A major injection at LANL 90 \\
\hline 04:29 & A small injection at LANL 90 & 05:02 & $\begin{array}{l}\text { Onset of substorm intensification at FCC in } \\
\text { the midnight sector }\end{array}$ \\
\hline 04:48-04:49 & $\begin{array}{l}\text { Onset of ground magnetic disturbances at } \\
\text { FCC and PBQ in the midnight sector }\end{array}$ & 05:03-05:05 & $\begin{array}{l}\text { Ground magnetic disturbances spreading } \\
\text { over both the pre-midnight to post-midnight } \\
\text { sectors }\end{array}$ \\
\hline $04: 51$ & Sharp dipolarization at GOES 12 & 05:03 & A significant dipolarization at GOES 12 \\
\hline $04: 57$ & Small dipolarization at Geotail & 05:07 & $\begin{array}{l}\text { Dipolarization with significant plasma flow } \\
\text { and electric field at Geotail }\end{array}$ \\
\hline 04:59 & $\begin{array}{l}\text { Onset of large fluctuations in electric field at } \\
\text { Polar }\end{array}$ & $05: 11$ & Sharp dipolarization at Polar \\
\hline $05: 25$ & $\begin{array}{l}\text { Plasma sheet expansion and dipolarization } \\
\text { with earthward plasma flow }\end{array}$ & $05: 40$ & $\begin{array}{l}\text { Significant dipolarization without plasma } \\
\text { flow at Cluster }\end{array}$ \\
\hline Time sequence & LANL90- GOES 12- Geotail- Polar-Cluster & Time sequence & LANL90- GOES 12- Geotail- Polar-Cluster \\
\hline
\end{tabular}

corrected geomagnetic latitude and longitude at 05:00 UT, LANL 90 is projected to $\left(62.8^{\circ}, 34.8^{\circ}\right)$, GOES 12 is projected to $\left(62.9^{\circ}, 356.2^{\circ}\right)$, Polar is projected to $\left(64.5^{\circ}, 33.0^{\circ}\right)$, Geotail is projected to $\left(64.8^{\circ}, 23.0^{\circ}\right)$, and Cluster is projected to $\left(69.4^{\circ}, 35.5^{\circ}\right)$. This study emphasizes the important role played by observations from ground-based magnetometers in sorting out the time sequence development.

If the time sequence of substorm disturbance were dominated by the magnetic local time, the expected time sequence would be Cluster, LANL 90, Polar, Geotail, and GOES 12 for the substorm disturbance spreading from the post-midnight sector to the midnight sector. This clearly is not consistent with the observed time sequence. It is also not consistent with substorm disturbance spreading from the midnight sector to the post-midnight sector, based on the ground activity time sequence as well as the magnetotail activity onset sequence. On the other hand, if the time sequence were dominated by the magnetic latitude and starts from low latitude to high latitude, then the expected time sequence would be LANL 90, GOES 12, Polar, Geotail, and Cluster. The specific corrected geomagnetic latitudes for these satellites are $62.8^{\circ}$ for LANL $90,62.9^{\circ}$ for GOES $12,64.5^{\circ}$ for Polar, $64.8^{\circ}$ for Geotail, and $69.4^{\circ}$ for Cluster. The observed time sequence can be considered consistent with this if the order for Polar and Geotail is interchanged. This is not too surprising since the difference in the corrected geomagnetic latitude between Polar and Geotail is very small, $\sim 0.3^{\circ}$, and the dipolarization has an irregular front based on multisatellite observations (Lopez and Lui, 1990). Therefore, the observed time sequence shows that the substorm activities for the two intensifications are consistent with propagation dominated by magnetic latitude and proceeding from the low latitude, i.e., the near-Earth region, to the high latitude region, i.e., the mid-tail region.

\subsection{Other discriminating substorm features}

Even though this study focuses mainly on dipolarization in the magnetotail for comparison with ground activity, the associated parameters such as plasma flow and electric field in the magnetotail should be considered in differentiating the two substorm models. For the mid-tail initiation model, dipolarization should be preceded by at least $1-2$ min of significant earthward plasma flow to allow for the transit time for plasma flow to reach the near-Earth region and slow down to cause near-Earth dipolarization before the mid-tail dipolarization. For this scenario, the $y$-component of the electric field at the observing satellite location must be positive in order to carry the magnetic flux earthward. In Geotail for the dipolarization at 05:07 UT, the plasma flow perpendicular to the magnetic field had a larger $y$-component than the $x$ component, thus deflecting the transport of magnetic flux in the dawn-dusk direction rather than in the earthward direction. In addition, the electric field was intermittently dawnward instead of duskward for earthward transport of magnetic flux. In Cluster for the dipolarization at $\sim 05: 40 \mathrm{UT}$, there was no significant plasma flow and the $y$-component of the electric field was negative $\left(E_{y}=-3.7 \mathrm{mV} / \mathrm{m}\right)$. These features are not consistent with earthward transport of magnetic flux.

3.4 Other possible interpretation of time sequence of substorm activity

One could in principle attempt to construct a different time sequence from the data. For example, one may assign dipolarization at Geotail to be at $\sim 04: 45$ UT and interpret the time sequence as due to substorm disturbance expanding eastward. However, this interpretation is inconsistent not 
only with an earlier injection occurring at $\sim 04: 29$ UT in the LANL 90 data but also with the lack of an accompanying decrease in the $B_{x}$ component that implies decrease in the cross-tail current related to dipolarization as well as with the lack of plasma flow.

Another attempt may be to disregard the first minor intensification at $\sim 04: 27$ UT since the particle injection at LANL 90 was weak and interpret the second intensification at $\sim 04: 54$ UT as the only activity onset. However, this attempt would have difficulty in explaining the double activity onsets separated by about 10-15 min apart at GOES 12, Polar, Geotail, and Cluster. Furthermore, considering the first intensification as a pseudobreakup is not consistent with the occurrence of the large magnetic perturbations at LRV at these times ( $\sim 400 \mathrm{nT}$ at 04:27 UT and $\sim 650 \mathrm{nT}$ at 04:48 UT) and the substantial auroral activity revealed by the TIMED image at 04:44 UT (second image in the bottom row of Fig. 1) as well as the auroral intensification at 04:48 UT seen by the VIS Earth camera on Polar as mentioned in Sect. 2.1.

In terms of Cluster observations, one might pick the times of 05:14 and 05:25 UT to correspond to the two onsets of ground magnetic activity. However, this choice has difficulty. For example, there was no indication that Cluster entered the central plasma sheet at 05:14 UT (see the number density plot in Fig. 9). Furthermore, even if the earlier times were chosen, the time sequence of activity as tabulated in Table 1 would have remained the same. Therefore, the conclusion will not be altered by this change.

3.5 Spreading of substorm disturbance in the current disruption model

Another point that warrants clarification is the spreading of dipolarization. In the current disruption model for substorms (Lui, 1991; Lui et al., 1991), a current-driven plasma instability disrupting the cross-tail current can instigate development of the same instability in adjacent regions of the tail, both tailward and dawnward/duskward sides of the current disruption site. The rarefaction wave generated by a current disruption site merely thins the adjacent plasma sheet and subsequently enhances the cross-tail current density to establish a more favorable onset condition of the current-driven plasma instability. Whether the instability will indeed be initiated depends highly on the local conditions. When the instability threshold is reached, a certain amount of time is required for the instability to develop to the nonlinear stage so that significant current disruption and dipolarization can occur. This scenario thus expects a rather non-uniform spreading of dipolarization region in the tail, as found by multi-satellite observations (e.g., Lopez and Lui, 1990). Furthermore, this scenario can account for observations in which the plasma flow can deviate by a large angle from the normal of the dipolarization front as reported by Nakamura et al. (2002). Plasma flow is a result of force imbalance in current disruption and is not a direct cause of dipolarization. Therefore, the spread- ing of dipolarization is expected to deviate from any wave speed or convection speed, as shown by several reports (e.g., Jacquey et al., 1991; Ohtani, 1993; Pu et al., 2001; Nakamura et al., 2002). This is consistent with the finding that current disruption and dipolarization is a non-MHD process (Lui et al., 1999). Thus, relating convection and speed of various plasma waves to the averaged speed in the spreading of dipolarization is not meaningful.

\subsection{Final remark}

Finally, we emphasize that the present result does not diminish the importance of the THEMIS mission in resolving the substorm onset problem since not all satellites in this study are in the equatorial plane like the THEMIS satellites. Not all satellites have identical data sets for the investigation. This study is also hampered by the lack of continuous coverage of global auroral and magnetic activities. These deficiencies make the analysis on the onset location of substorm activity difficult and the result less readily comprehensible. Furthermore, this study on this single time interval does not necessarily represent other substorm intervals and may not provide compelling evidence for the origin of substorm disturbance location in the magnetotail. However, a collection of similar events showing a similar temporal trend for the spreading of substorm disturbance in the magnetotail would constitute convincing determination on the location of substorm activity onset. This study only provides a glimpse of what THEMIS might observe.

Acknowledgements. This work was supported by the NSF grant ATM-0630912 and NASA grant NNG04G128G to The Johns Hopkins University Applied Physics Laboratory. We thank H. Singer for GOES 12 data and his comments on an earlier draft.

Topical Editor I. A. Daglis thanks two referees for their help in evaluating this paper.

\section{References}

Balogh, A., Carr, C. M., Acuna, M. H., et al.: The Cluster magnetic field investigation: overview of in-flight performance and initial results, Ann. Geophys., 19, 1207-1217, 2001, http://www.ann-geophys.net/19/1207/2001/.

Cheng, C. Z.: Physics of substorm growth phase, onset, and dipolarization, Space Sci. Rev., 113, 207-270, 2004.

Cheng, C. Z. and Lui, A. T. Y.: Kinetic ballooning instability for substorm onset and current disruption observed by AMPTE/CCE, Geophys. Res. Lett., 25, 4091-4094, 1998.

Donovan, E., Mende, S., Jackel, B., et al.: The THEMIS all-sky imaging array - system design and initial results from the prototype imager, J. Atmos. Solar Terr. Phys., 68(13), 1472-1487, 2006.

Haerendel, G.: Disruption, ballooning or auroral avalanche, Proceedings of the First International Conference on Substorms, ESA SP-335, Kiruna, Sweden, 23-27 March 1992, 417, 1992. 
Gustafsson, G., Boström, R., Holback, B., et al.: The electric field and wave experiment for the Cluster mission, Space Sci. Rev., 79, 137-156, 1997.

Jacquey, C., Sauvaud, J. A., and Dandouras, J.: Location and propagation of the magnetotail current disruption during substorm expansion: analysis and simulation of an ISEE multi-onset event, Geophys. Res. Lett., 18, 389-392, 1991.

Lopez, R. E. and Lui, A. T. Y.: A multisatellite case study of the expansion of a substorm current wedge in the near-earth magnetotail, J. Geophys. Res., 95, 8009-8018, 1990.

Lui, A. T. Y.: A synthesis of magnetospheric substorm models, J. Geophys. Res., 96, 1849-1856, 1991.

Lui, A. T. Y.: Potential plasma instabilities for substorm expansion onset, Space Sci. Rev., 113, 127-206, 2004.

Lui, A. T. Y., Chang, C.-L., Mankofsky, A., et al.: A cross-field current instability for substorm expansions, J. Geophys. Res., 96, $11389-11401,1991$.

Lui, A. T. Y., Liou, K., Nosé, M., et al.: Near-Earth dipolarization: Evidence for a non-MHD process, Geophys. Res. Lett., 26, 2905-2908, 1999.

Lui, A. T. Y., Liou, K., Newell, P. T., et al.: Conjunction of tail satellites for substorm study: ISTP event of 1997 January 2, Geophys. Res. Lett., 27, 1831-1834, 2000.

Lyons, L. R., Wang, C.-P., and Nagai, T.: Substorm onset by plasma sheet divergence, J. Geophys. Res., 108(A12), 1427, doi:10.1029/2003JA010178, 2003.

Nagai, T., Fujimoto, M., Saito, Y., et al.: Structure and dynamics of magnetic reconnection for substorm onsets with Geotail observations, J. Geophys. Res., 103, 4419-4440, 1998.

Nakamura, R., Baumjohann, W., Klecker, B., et al.: Motion of the dipolarization front during a flow burst event observed by Cluster, Geophys. Res. Lett., 29(20), 1942, doi:10.1029/2002GL015763, 2002.
Ohtani, S.-I.: On the tailward expansion of current disruption during substorms, Adv. Space Res., 13(4), 265-268, 1993.

$\mathrm{Pu}, \mathrm{Z}$. Y., Korth, A., Kang, K. B., et al.: Drift ballooning instability in the presence of a plasma flow: A synthesis of tail reconnection and current disruption for the initiation of substorms, J. Geophys. Res., 104, 10235-10 248, 1999.

Pu, Z. Y., Korth, A., Chen, Z. X., et al.: A global synthesis model of dipolarization at substorm expansion onset, J. Atmos. Solar-Terr. Phys., 63, 671-681, 2001.

Rème, H., Bosqued, J. M., Sauvaud, J. A., et al.: First multispacecraft ion measurements in and near the Earth's magnetosphere with the identical Cluster ion spectrometry (CIS) experiment, Ann. Geophys., 19, 1303-1354, 2001, http://www.ann-geophys.net/19/1303/2001/.

Roux, A., Perraut, S., Robert, P., et al.: Plasma sheet instability related to the westward traveling surge, J. Geophys. Res., 96, 17 697-17 714, 1991.

Sergeev, V. A., Kubyshkina, M. V., Baumjohann, W., et al.: Transition from substorm growth to substorm expansion phase as observed with a radial configuration of ISTP and Cluster spacecraft, Ann. Geophys., 23, 2183-2198, 2005, http://www.ann-geophys.net/23/2183/2005/.

Shiokawa, K., Baumjohann, W., and Haerendel, G.: Braking of high-speed flows in the near-Earth tail, Geophys. Res. Lett., 24, 1179-1182, 1997.

Shiokawa, K., Haerendel, G., and Baumjohann, W.: Azimuthal pressure gradient as driving force of substorm currents, Geophys. Res. Lett., 25, 959-962, 1998. 